\title{
Sexual size and shape dimorphism in two species of newts, Triturus cristatus and T. vulgaris (Caudata: Salamandridae)
}

Jan C. Malmgren* and Mikael Thollesson $\dagger$

Department of Zoology, Göteborg University, Box 463, SE-405 30 Göteborg, Sweden

(Accepted 13 November 1998)

\begin{abstract}
Morphometric data from Fennoscandian populations of the crested newt Triturus cristatus and the smooth newt Triturus vulgaris were analysed for the presence of sexual size and shape dimorphism. The data sets included nine body-related and nine head-related measurements and were examined with univariate, bivariate and multivariate methods. Sexual dimorphism was demonstrated in both species. The separation of specimens was highly related to sex. Although the expression of sexual dimorphism differed between the two species, some patterns were shared. These are discussed in terms of evolution of intersexual dimorphism according to models of ecology, fecundity and sexual selection. In multivariate analyses, sexual dimorphism was restricted to body-related variables such as standard length and distance of extremities (with high values for females), contrasting against cloaca and limb-related characters (with high values for males). In both species, the 'distance of extremities' measure (i.e. trunk length) was one of the strongest sexually dimorphic traits. No evidence of sexual dimorphism in head morphology was found. The results are interpreted as primarily concordant with theories on fecundity selection. For example, it has been suggested that females with larger trunk volumes increase their reproductive capacity. The fact that males had longer extremities, in relation to other characters measured, could be attributed to sexual selection. Long limbs in male newts may be beneficial for courtship performance. Since head-related characters did not show any patterns of sexual dimorphism, no evidence was found to suggest that male and female crested and smooth newts have adapted to different feeding strategies.
\end{abstract}

Key words: Triturus cristatus, Triturus vulgaris, sexual dimorphism, sexual selection, fecundity

\section{INTRODUCTION}

Sexual dimorphism is defined as a phenotypic difference between males and females of a species. Dimorphic traits are often easily observable (e.g. relating to body size, morphological traits, ornaments, coloration, etc.), but may also be more subtle (e.g. glandular structure, pheromone secretion and epidermal texture). In general, permanently dimorphic traits are primarily influenced by developmental processes and growth prior to maturity (Shine, 1990), whereas secondary sexual traits are mainly under hormonal and seasonal influence (Andersson, 1994). As a consequence, the latter characters are often less permanent, more seasonally variable and often coupled to reproduction. However, ecological factors (e.g. food availability, predation, etc.) also

\footnotetext{
*All correspondence to: Department of Technology and Science, Section of Biology, Örebro University, SE-701 82 Örebro, Sweden. E-mail: Jan.Malmgren@ton.oru.se

$\dagger$ Present address: Department of Invertebrate Zoology, National Museum of Natural History, Smithsonian Institution, Washington, DC 20560-0163, U.S.A. E-mail: Thollesson@1ms.si.edu
}

contribute to the extent of expression in both (Endler, 1983; Shine, 1989).

Sexual dimorphism is widespread among organisms (Darwin, 1871; Andersson, 1994). It can be thought of as the phenotypic result of a genetic polymorphism maintained by frequency-dependent selection (Maynard Smith, 1989), and there are several different hypotheses concerning its evolution (see reviews by e.g. Shine, 1979, 1989; Slatkin, 1984; Andersson, 1994; Reynolds \& Harvey, 1994; Fairbairn, 1997). If simplified, the processes underlying sexual dimorphism can be understood in terms of intersexual differences in (1) ecology, (2) fecundity, or (3) sexual selection (Hedrick \& Temeles, 1989). The first of these alternatives (the ecological model) relates to the idea that sexes differ because they have adapted to different resource utilisation through niche partitioning and subsequent character displacement. Among other things, this model predicts that males and females should differ in, for example, trophic structures (i.e. mouth or head morphology). Under the second hypothesis (the fecundity model), sexual dimorphism is believed to evolve when one sex (most 
often females) benefits more from a large body size than the other sex, in terms of reproductive outcome. This hypothesis predicts that intersexual differences in characters should be related to fecundity. For example, in egg-laying species females could have a longer and more voluminous abdomen than males, in order to support a large number of eggs (e.g. Shine, 1988). According to this model, sexual dimorphism can also be viewed as a life history adaptation (Endler, 1983). The third alternative theory (the sexual selection model) treats sex differences in external morphology (e.g. body proportions, ornaments, coloration, etc.) as having evolved by, for example, the active selection of epigamic features on one sex by the other. This suggests that individuals (most often males) with enlarged traits have an advantage in competition for mates relative to other individuals of the same sex (Andersson, 1994).

The main difference between these three alternative models pertains to the underlying selection process. For example, theories relating to differences in ecology and fecundity generally assume that natural selection is the force responsible for their evolution. Sexual dimorphism is in this view clearly an adaptation. Epigamic features (ornaments, coloration, etc.), however, can be under the influence of sexual selection through competition over mates or directed mate choice. Epigamic traits, though they can admittedly be of adaptive value, are thus often assumed to evolve without the interference of natural selection - in some cases even in its opposed direction. However, it is not always necessary to distinguish between products of natural and sexual selection in studies of sexual dimorphism. It can be equally fruitful to consider dimorphic characters in terms of the net outcome of different selection pressures operating simultaneously on males and females (Hedrick \& Temeles, 1989; Mace, 1992).

In amphibians, females generally grow larger than males and female body size is often correlated to clutch size (e.g. Duellman \& Trueb, 1986). In species where males are the larger sex this can be attributed to high degrees of male interactions such as combat during the reproductive season (Shine, 1979; but see also Halliday \& Verrell, 1986). European newts of the genus Triturus show a high degree of sexual dimorphism (see e.g. Halliday \& Arano, 1991; Kalezic, Crnobrnja et al., 1992; Andersson, 1994). The most strikingly dimorphic characters are seasonal - all species in this group have elaborate aquatic lekking behaviour where male coloration and the development of dorsal crests are important traits for a male's reproductive success (e.g. Halliday, 1977; Malacarne \& Cortassa, 1983; Hedlund, 1990). Most species also show permanent sexual differences in morphology. For example, females are generally larger in body size than males (e.g. Rafinski \& Pecio, 1989; Kalezic, Crnobrnja et al., 1992), with one of the few exceptions being the banded newt, T. vittatus. Incidentally, this is also the only representative with male-to-male aggressive lekking behaviour (Raxworthy, 1989).

In the present paper, we explore and discuss sexual size and shape dimorphism in two species of newts in
Table 1. Definitions of the morphological character set and abbreviations used for body- and head-related variables

Abbrevi-

ations Variable definition

Body measurements

STL Standard length, tip of snout to posterior margin of cloacal lips

TL Tail length, posterior margin of cloacal lips to tip of tail

GCL Groin-cloacal length, anterior margin of hind leg to posterior margin of cloacal lips

DEX Distance of extremities, posterior margin of front leg (axilla) to anterior margin of hind leg (groin)

UAL Upper arm length, posterior margin of front leg (axilla) to angle of elbow

LAL Lower arm length, angle of elbow to tip of the longest finger

THL Thigh length, anterior margin of hind leg (groin) to angle of knee

LLL Lower leg length, angle of knee to tip of the longest toe

ELL Eye-front leg length, anterior margin of eye to posterior margin of front leg (axilla)

\section{Head measurements}

$\mathrm{HH} \quad$ Height of head, margin of lower jaw to roof of skull, in line with the eyes

HL Head length, tip of snout to posterior region of neck

SEL Snout-eye length, tip of snout to anterior margin of eye

DN Distance of nostrils, from one nostril to the other

NEL Nostril-eye length, nostril to anterior margin of eye

ED Eye diameter, anterior to posterior margin of eye

IOD Interorbital distance, shortest distance between eyes (from a dorsal view)

HW Head width, largest width of head, in line with the corner of the mouth

ML Mouth length, tip of snout to the corner of the mouth

northernmost Europe - the crested newt Triturus cristatus and the smooth newt $T$. vulgaris. We aim to describe the expression of intersexual differences in the two species and discuss their evolution, as outlined above. By using multivariate statistics, it is possible to analyse how single traits may co-vary with other traits within sexes to influence the general pattern of sexual dimorphism. Our conclusions suggest that niche partitioning in terms of feeding is not a likely determinant of sexual dimorphism in the two newts. Instead, fecundity and, possibly, epigamic selection seem more plausible processes underlying the observed dimorphism in the two species.

\section{MATERIALS AND METHODS}

We studied sexual dimorphism in preserved specimens of crested and smooth newts from museum collections in Sweden, Norway, Denmark and Finland (see Appendix). Eighteen variables (Table 1) were measured with callipers by the first author (JCM) to the nearest $0.1 \mathrm{~mm}$ in a standardized manner. Only adult specimens 
Table 2. Descriptive statistics on body- and head-related variables for the crested newt, Triturus cristatus (71 females, 43 males $(n=114)$ ), with results from univariate tests on sexual dimorphism (two-tailed $t$-test, $\alpha=0.05$ )

\begin{tabular}{|c|c|c|c|c|c|}
\hline \multirow[b]{2}{*}{ Variable } & \multicolumn{2}{|c|}{ Males } & \multicolumn{2}{|c|}{ Females } & \multirow[b]{2}{*}{$P$} \\
\hline & Mean $\pm \mathrm{SE}$ & Range & Mean $\pm \mathrm{SE}$ & Range & \\
\hline \multicolumn{6}{|l|}{ Body } \\
\hline STL & $67.33 \pm 0.83$ & $54.0-78.7$ & $71.21 \pm 0.61$ & $59.4-82.9$ & 0.0002 \\
\hline $\mathrm{TL}$ & $47.56 \pm 0.70$ & $38.4-54.9$ & $53.88 \pm 0.56$ & $42.1-62.2$ & 0.0000 \\
\hline GCL & $12.09 \pm 0.22$ & $9.6-15.0$ & $10.32 \pm 0.12$ & $7.6-12.8$ & 0.0000 \\
\hline DEX & $32.97 \pm 0.56$ & $26.6-40.0$ & $37.73 \pm 0.45$ & $29.5-47.4$ & 0.0000 \\
\hline UAL & $6.98 \pm 0.11$ & $5.8-9.9$ & $6.70 \pm 0.08$ & $5.0-8.3$ & 0.0426 \\
\hline LAL & $14.77 \pm 0.21$ & $11.3-17.9$ & $13.79 \pm 0.14$ & $8.0-16.4$ & 0.0001 \\
\hline THL & $8.02 \pm 0.10$ & $6.8-10.4$ & $7.80 \pm 0.09$ & $6.1-9.4$ & 0.1249 \\
\hline LLL & $17.87 \pm 0.25$ & $13.8-21.5$ & $16.17 \pm 0.13$ & $13.8-19.5$ & 0.0000 \\
\hline ELL & $17.72 \pm 0.18$ & $15.0-19.8$ & $18.20 \pm 0.13$ & $15.9-21.9$ & 0.0311 \\
\hline \multicolumn{6}{|l|}{ Head } \\
\hline $\mathrm{HH}$ & $5.78 \pm 0.09$ & $4.8-8.0$ & $5.90 \pm 0.07$ & $4.4-7.3$ & 0.2769 \\
\hline $\mathrm{HL}$ & $16.53 \pm 0.17$ & $11.8-18.6$ & $17.09 \pm 0.12$ & $14.6-20.0$ & 0.0056 \\
\hline SEL & $5.25 \pm 0.06$ & $4.3-6.2$ & $5.35 \pm 0.05$ & $4.3-6.3$ & 0.2385 \\
\hline $\mathrm{DN}$ & $2.91 \pm 0.06$ & $2.0-4.1$ & $2.87 \pm 0.03$ & $2.3-3.6$ & 0.5059 \\
\hline NEL & $3.73 \pm 0.05$ & $3.1-4.4$ & $3.77 \pm 0.04$ & $3.0-4.9$ & 0.5272 \\
\hline ED & $3.76 \pm 0.04$ & $3.1-4.4$ & $3.70 \pm 0.05$ & $2.9-4.8$ & 0.3514 \\
\hline IOD & $3.79 \pm 0.07$ & $3.0-4.9$ & $3.95 \pm 0.05$ & $2.6-4.9$ & 0.0592 \\
\hline $\mathrm{HW}$ & $10.61 \pm 0.11$ & $9.0-12.3$ & $10.79 \pm 0.10$ & $9.1-12.8$ & 0.2373 \\
\hline ML & $9.90 \pm 0.09$ & $8.8-11.4$ & $10.10 \pm 0.09$ & $8.6-12.3$ & 0.1369 \\
\hline
\end{tabular}

Table 3. Descriptive statistics on body- and head-related variables for the smooth newt, Triturus vulgaris (72 females, 88 males $(n=160))$, with results from univariate tests on sexual dimorphism (two-tailed $t$-test, $\alpha=0.05)$

\begin{tabular}{|c|c|c|c|c|c|}
\hline \multirow[b]{2}{*}{ Variable } & \multicolumn{2}{|c|}{ Males } & \multicolumn{2}{|c|}{ Females } & \multirow[b]{2}{*}{$P$} \\
\hline & Mean $\pm \mathrm{sE}$ & Range & Mean $\pm \mathrm{SE}$ & Range & \\
\hline \multicolumn{6}{|l|}{ Body } \\
\hline STL & $40.40 \pm 0.28$ & $35.1-47.4$ & $40.91 \pm 0.41$ & $34.8-47.2$ & 0.2904 \\
\hline $\mathrm{TL}$ & $37.51 \pm 0.38$ & $28.8-44.1$ & $34.81 \pm 0.39$ & $26.7-41.9$ & 0.0000 \\
\hline GCL & $7.37 \pm 0.09$ & $5.4-9.8$ & $6.21 \pm 0.08$ & $4.6-7.8$ & 0.0000 \\
\hline DEX & $18.97 \pm 0.18$ & $15.8-23.8$ & $20.38 \pm 0.26$ & $16.2-24.6$ & 0.0000 \\
\hline UAL & $4.74 \pm 0.06$ & $3.0-5.8$ & $4.53 \pm 0.05$ & $3.6-5.6$ & 0.0107 \\
\hline LAL & $9.57 \pm 0.09$ & $8.0-12.7$ & $8.70 \pm 0.08$ & $7.0-10.0$ & 0.0000 \\
\hline THL & $5.29 \pm 0.06$ & $3.6-6.9$ & $5.11 \pm 0.07$ & $3.5-6.7$ & 0.0610 \\
\hline LLL & $10.80 \pm 0.11$ & $8.6-13.0$ & $9.50 \pm 0.08$ & $8.0-10.9$ & 0.0000 \\
\hline ELL & $11.20 \pm 0.08$ & $9.6-13.2$ & $11.14 \pm 0.11$ & $9.2-13.1$ & 0.6250 \\
\hline \multicolumn{6}{|l|}{ Head } \\
\hline $\mathrm{HH}$ & $3.79 \pm 0.04$ & $3.1-5.1$ & $3.73 \pm 0.05$ & $3.1-5.5$ & 0.3528 \\
\hline $\mathrm{HL}$ & $10.39 \pm 0.08$ & $8.9-12.1$ & $10.42 \pm 0.11$ & $8.9-12.7$ & 0.8550 \\
\hline SEL & $3.42 \pm 0.03$ & $2.6-4.2$ & $3.37 \pm 0.03$ & $2.7-4.2$ & 0.1971 \\
\hline $\mathrm{DN}$ & $1.85 \pm 0.02$ & $1.4-2.9$ & $1.88 \pm 0.02$ & $1.5-2.5$ & 0.3185 \\
\hline NEL & $2.42 \pm 0.03$ & $1.8-3.0$ & $2.36 \pm 0.03$ & $1.8-3.0$ & 0.1929 \\
\hline ED & $2.82 \pm 0.03$ & $2.2-3.4$ & $2.64 \pm 0.04$ & $1.6-3.4$ & 0.0003 \\
\hline IOD & $2.47 \pm 0.03$ & $1.9-3.3$ & $2.38 \pm 0.03$ & $1.7-3.1$ & 0.0307 \\
\hline HW & $6.49 \pm 0.05$ & $5.6-9.0$ & $6.52 \pm 0.06$ & $5.5-7.7$ & 0.7089 \\
\hline ML & $6.26 \pm 0.05$ & $4.9-7.6$ & $6.22 \pm 0.06$ & $5.2-7.9$ & 0.5934 \\
\hline
\end{tabular}

collected in breeding condition and without apparent injuries were chosen, and obvious secondary sexual characters under seasonal influence (e.g. male dorsal crests) were excluded in order to focus on permanent traits. It was not possible to determine the age of specimens in this study (e.g. by using skeletochronology), since they were part of museum collections.

Amphibians shrink when preserved in alcohol or formalin, especially during the first 2-5 years (Dolmen, 1983; Verrell, 1985; Kalezic, Dzucic et al., 1990;
T. Hagström, pers. comm.). To avoid bias introduced from this, all specimens measured had been preserved for more than 5 years. This limited the number of available specimens, although the final sample (71 females, 43 males $T$. cristatus $(n=114)$; and 72 females, 88 males $T$. vulgaris $(n=160)$ represents a random selection of newts from the Fennoscandian distributions. The sampling area includes 2 formerly recognized subspecies of the smooth newt, T. vulgaris vulgaris and $T$. v. borealis, but the latter taxon is not readily 

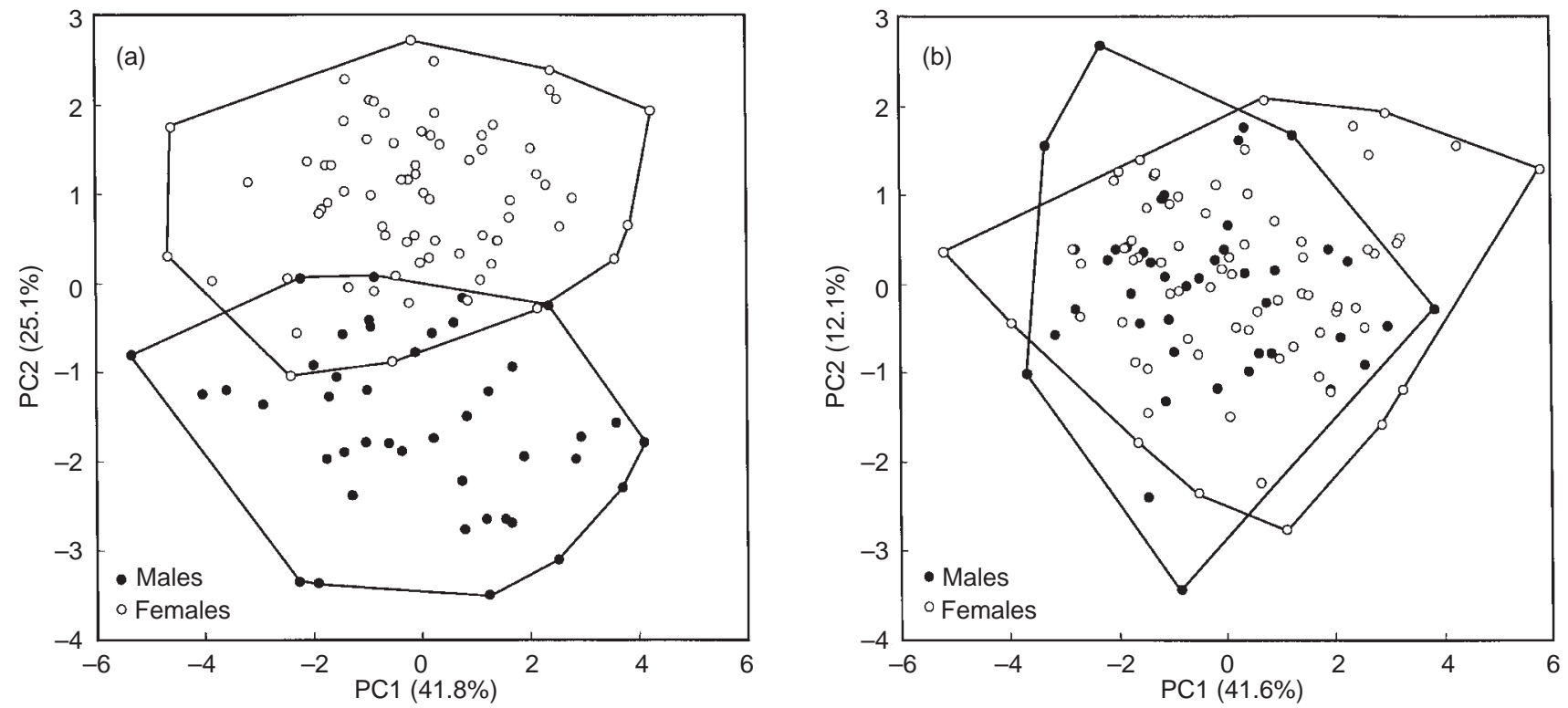

Fig. 1. Principal component analysis (PCA) on sexual dimorphism in the crested newt, Triturus cristatus. Scatterplots of principal component scores for the first two principal axes, with convex polygons for males and females. Loadings are shown in Table 4. (a) Body-related characters. There is no significant intersexual difference on the general size component (PC1; $t=-0.21$, NS), whereas on the shape component there is a significant distinction between the means of males $v s$ females (PC2; $t=15.05$, $P<0.001$ ). Least-square regression slopes (not drawn in figure) does not differ significantly between sexes $(t=2.05, P=0.043$; $\alpha=0.01)$. (b) Head-related variables. Significant sex differences are noted on neither PC1 $(t=-1.65$, NS), nor PC2 ( $t=0.55$, NS).

distinguishable and is currently treated as synonymous to the nominate form (see discussion in Raxworthy, 1990). Since the examined material consisted of small samples from many scattered locations, it was not possible to evaluate intra- or interpopulational variation. Differences in climate among sampled localities may also have introduced geographical variation in the material. However, we have preferred to treat this as a source of random variation and do not expect that it should significantly mask the existence of any systematic patterns of intersexual differences in multivariate analyses. The latter assumption is supported by preliminary analyses on the Fennoscandian newts, where the sexes had to be treated separately in order to evaluate geographical patterns in morphology.

Each variable was analysed for normality with graphical methods by eye and tested for differences in means between sexes using univariate and bivariate statistics (Z-tests and Student's $t$-test; $\alpha=0.05$ for all tests except for least square regression slope test, $\alpha=0.01$ ). In multivariate analyses the variables were partitioned into 2 sets (head- and body-related measurements) and were analysed separately using principal components analysis (PCA, e.g. Jackson, 1991; Manly, 1994) based on Pearson's correlation coefficients. Differences between the sexes were also tested with Wilk's lambda and Fisher's $F$-test in a discriminant function analysis, where sex was set as a priori groups. Furthermore, all observations were subjected to a reclassification analysis in order to establish how well the model derived from the discriminant analysis described intersexual differences. All calcula- tions were performed in Microsoft ${ }^{\circledR}$ Excel ${ }^{(m)} 97$ (for PC) using the add-in program $x l$ STAT Pro+ 3.0 (Fahmy, 1997).

\section{RESULTS}

Both species of newts were significantly sexually dimorphic in several body-related measurements (Tables $2 \& 3$ ). In contrast, there were fewer such sexrelated differences in measurements related to head morphology. The mean male to female standard length (STL) ratio was 0.946 for Triturus cristatus and 0.988 for T. vulgaris (data from Tables $2 \& 3$ ). In bivariate analyses, standard length (STL) in relation to the total length (measured from tip-of-snout to tip-of-tail), was dimorphic in both $T$. cristatus (males $58.6 \% \pm 0.26 \mathrm{SE}$, females $57.0 \% \pm 0.19$ se; $\quad Z=5.16, \quad P<0.001)$ and T. vulgaris (males $51.9 \% \pm 0.20 \mathrm{sE}$, females $54.0 \% \pm 0.22$ SE; $Z=-7.18, P<0.001)$. The direction of dimorphism differed between the two species in the relation of tail length (TL) to total length. Males of T. cristatus had the shorter tail (males $41.4 \% \pm 0.26 \mathrm{se}$, females $43.0 \% \pm 0.19$ SE; $Z=-5.16, P<0.001)$, whilst the reverse was true for T. vulgaris (males $48.1 \% \pm 0.20 \mathrm{sE}$, females $46.0 \% \pm 0.22$ SE; $Z=7.18, P<0.001)$. The relation between distance of extremities (DEX) to STL, differed significantly between sexes of both species in favour of large measurements in females (T. cristatus: males $48.9 \% \pm 0.45$ SE, females $52.9 \% \pm 0.30$ sE; $Z=-7.44, \quad P<0.001$; T. vulgaris: males $46.9 \% \pm 0.24 \mathrm{SE}$, females $49.8 \% \pm 0.31$ SE; $Z=-7.39, P<0.001)$. 

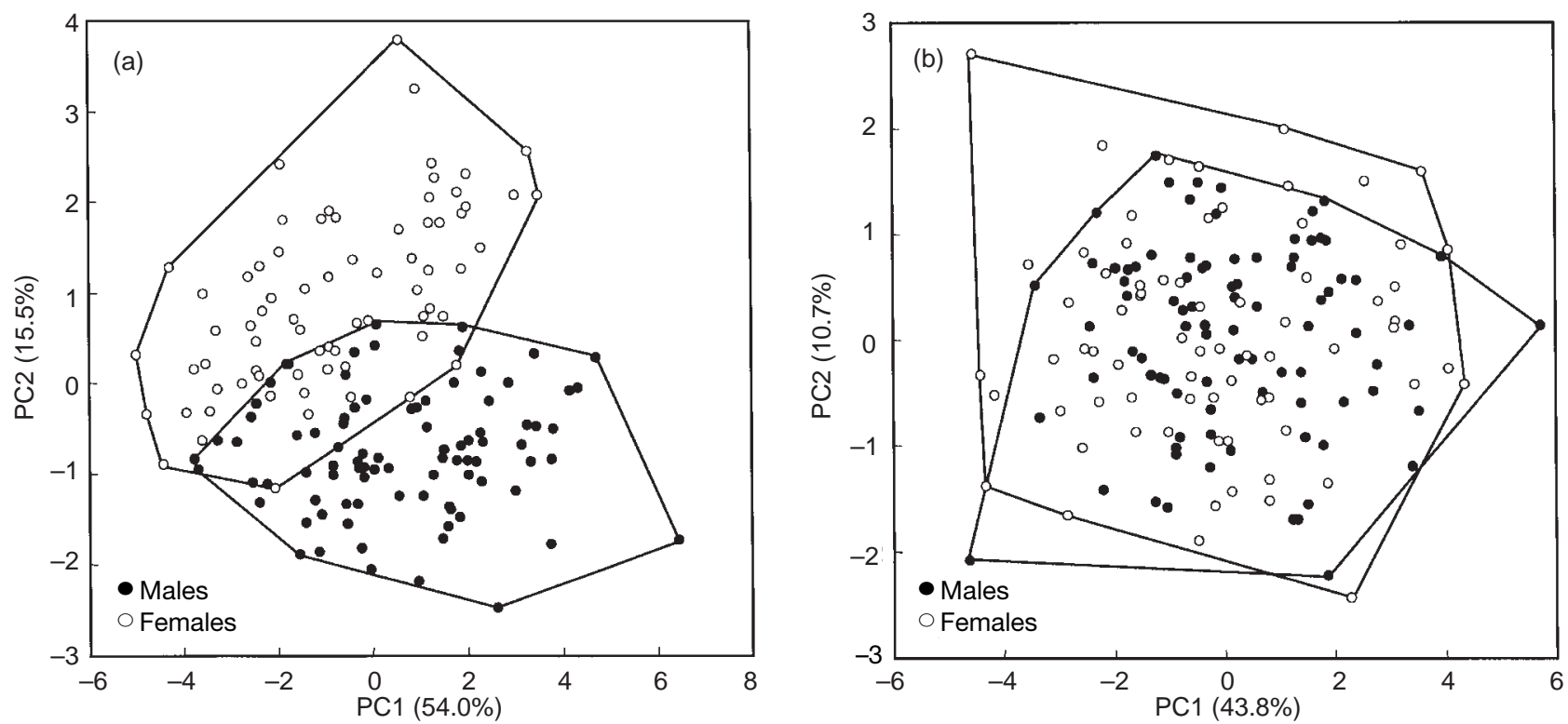

Fig. 2. Principal component analysis (PCA) on sexual dimorphism in the smooth newt, Triturus vulgaris. Scatterplots of principal component scores for the first two principal axes, with convex polygons for males and females. Loadings are shown in Table 4. (a) Body-related characters. Significant intersexual differences in the means of males $v s$ females are noted in both size (PC1; $t=4.19, P<0.001)$, and shape (PC2; $t=-13.06, P<0.001)$. Least-square regression slopes (not drawn in figure) differ significantly between sexes $(t=4.86, P<0.001 ;=0.01)$. (b) Head-related variables. Significant sex differences are noted on neither $\mathrm{PC} 1(t=1.26, \mathrm{NS})$, nor PC2 $(t=-0.22, \mathrm{NS})$.

Table 4. Factor loadings for the first two principal components (eigenvectors) for Triturus cristatus and T. vulgaris from multivariate analyses (principal components analysis, PCA) on body- and head-related variables

\begin{tabular}{|c|c|c|c|c|}
\hline \multirow[b]{2}{*}{ Variable } & \multicolumn{2}{|c|}{ Triturus cristatus } & \multicolumn{2}{|c|}{ Triturus vulgaris } \\
\hline & $\mathrm{PC} 1$ & PC2 & $\mathrm{PC} 1$ & $\mathrm{PC} 2$ \\
\hline \multicolumn{5}{|l|}{ Body } \\
\hline STL & 0.853 & 0.429 & 0.834 & 0.478 \\
\hline TL & 0.616 & 0.641 & 0.748 & -0.066 \\
\hline GCL & 0.535 & -0.596 & 0.681 & -0.499 \\
\hline DEX & 0.642 & 0.649 & 0.594 & 0.760 \\
\hline UAL & 0.562 & -0.265 & 0.630 & -0.192 \\
\hline LAL & 0.710 & -0.432 & 0.819 & -0.283 \\
\hline THL & 0.445 & -0.388 & 0.576 & -0.120 \\
\hline LLL & 0.591 & -0.659 & 0.842 & -0.339 \\
\hline ELL & 0.769 & 0.207 & 0.826 & 0.299 \\
\hline Eigenvalue & 3.763 & 2.256 & 4.862 & 1.396 \\
\hline$\%$ of variability & 41.8 & 25.1 & 54.0 & 15.5 \\
\hline Cumulated \% & 41.8 & 66.9 & 54.0 & 69.5 \\
\hline \multicolumn{5}{|l|}{ Head } \\
\hline $\mathrm{HH}$ & 0.650 & -0.080 & 0.656 & -0.369 \\
\hline HL & 0.687 & 0.128 & 0.813 & -0.160 \\
\hline SEL & 0.746 & 0.154 & 0.693 & 0.424 \\
\hline DN & 0.386 & -0.784 & 0.479 & 0.108 \\
\hline NEL & 0.626 & 0.506 & 0.647 & 0.545 \\
\hline ED & 0.574 & 0.095 & 0.571 & -0.453 \\
\hline IOD & 0.556 & -0.310 & 0.487 & 0.217 \\
\hline HW & 0.766 & -0.203 & 0.730 & -0.239 \\
\hline ML & 0.726 & 0.149 & 0.790 & 0.002 \\
\hline Eigenvalue & 3.744 & 1.086 & 3.939 & 0.960 \\
\hline$\%$ of variability & 41.6 & 12.1 & 43.8 & 10.7 \\
\hline Cumulated \% & 41.6 & 53.7 & 43.8 & 54.5 \\
\hline
\end{tabular}

In each PCA there were high positive loadings for all characters on PC1. This axis is therefore interpreted as a general size measure. Contrasting positive and negative loadings were found on PC2, indicating general shape measures as important for this separation. Again, body measurements gave a clear pattern of differences between the sexes in both $T$. cristatus and $T$. vulgaris, while head characters showed no such distinctions (Figs 1 \& 2). Factor loadings for principal components (Table 4) revealed that a total of $67 \%$ of the variability for T. cristatus, and correspondingly $70 \%$ for T. vulgaris, could be explained by the first two components (PC1 and $\mathrm{PC} 2$ ) for body-related traits. The remaining components (PC3-PC9) individually explained $<10 \%$ of the total variation for both species on body-related traits, and did not reveal any readily interpretable patterns.

A two-tailed $t$-test was applied to the PCA loadings on the first two axes to differentiate between means for males $v$ s females. In $T$. cristatus, body variables did not show a significant difference between the sexes for size (PC1; $t=-0.21, \mathrm{NS})$, but yielded a strong distinction on shape (PC2; $t=15.05, P<0.001)$. In short, females had large values for body-related measurements co-varying with short cloaca and limb-related measures - the reverse applied to males. Head characters showed no significant sex differences on either PC1 $(t=-1.65$, NS) or PC2 $(t=0.55, \mathrm{NS})$ in this species. In $T$. vulgaris, both PC1 $(t=4.19, \quad P<0.001)$ and PC2 $(t=-13.06$, $P<0.001)$ showed significant sex differences for body measurements, but neither PC1 $(t=1.26, \mathrm{NS})$, nor PC2 $(t=-0.22$, NS) supported sex differences for head- 

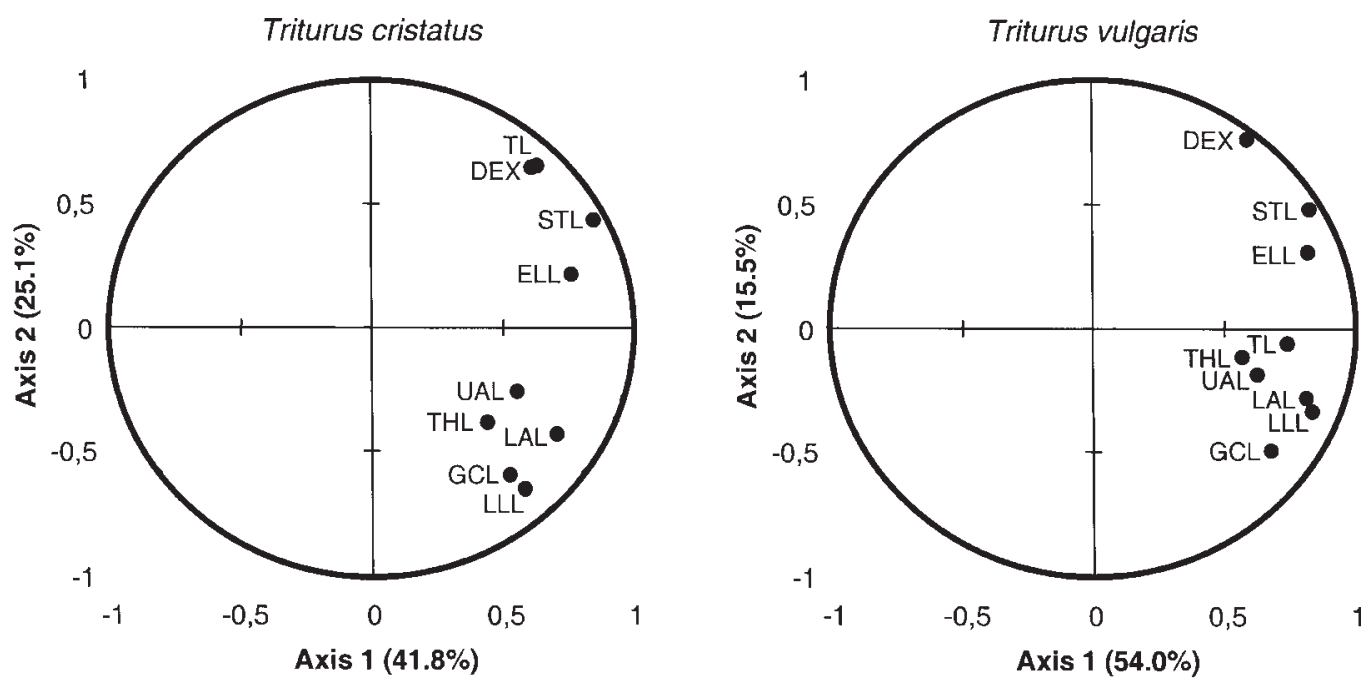

Fig. 3. Factor loadings for the first two principal components in analyses of body-related characters. Loadings on PC1 are all close to one and positive, and this component is interpreted as a general size measure. On PC2 positive loadings (characters above the abscissa) are contrasted with negative loadings (below), and the component is interpreted as a measure of shape that discriminates between males and females (Figs 1 \& 2). Patterns are similar for the two species, except for tail length (TL) that has opposite signs for PC2 loadings in the two species. Abbreviations as in Table 1.

related variables. The patterns were similar in both species.

The separation of specimens in multivariate analyses was highly related to sex in both species (Fig. 3). In general, sexual dimorphism corresponded to contrasts between body-size related variables (high values in females) versus cloaca and limb-related variables (high values in males) along the second axis (see loadings in Table 4). Sexual dimorphism in T. cristatus was in this context mainly due to large female measures for STL, TL, DEX and ELL (related to the body and tail), contrasted against large male measures for GCL, UAL, LAL, THL and LLL (which are cloacal and limb lengths). This distinction in shape is clearly seen along axis 2 in Fig. 3, where female and male measurements fall out above and below the abscissa, respectively (e.g. females have large values for DEX but low values for GCL - the opposite applies to males). The pattern in T. vulgaris was similar - females had large measures for body-related variables (i.e. STL, DEX and ELL), while males had large values for tail, cloaca and limb measures (i.e. TL, GCL, UAL, LAL, THL and LLL).

Shape differences (PC2) in body measures between the sexes increased with size (PC1) in T. vulgaris (see Fig. 2). Least-square regression slopes differed significantly between sexes $(t=4.86, P<0.001 ; \alpha=0.01)$. The same trend could also be found in $T$. cristatus (see Fig. 1), but was not statistically significant $(t=2.05$, $P=0.043 ; \alpha=0.01$.

Discriminant analyses with sexes defined as a priori groups, and successive tests with a posteriori reclassification analysis of observations, confirmed what we found in the PCA explorations above. In T. cristatus, sexes could be distinctly separated with the model established (Wilk's lambda $=0.265, F_{(9,106)}=42.76, P<0.001$ ), and $95.6 \%$ of all observations were correctly reclassified to sex (5 of 114 observations were incorrect). The same applied to $T$. vulgaris (Wilk's lambda $=0.307$, $\left.F_{(9,152)}=34.15, P<0.001\right)$. In this species $91.3 \%$ of the observations could be correctly reclassified to sex (14 of 160 observations were incorrect).

\section{DISCUSSION}

Neither $T$. cristatus nor $T$. vulgaris were sexually dimorphic in head-related variables. This is in agreement with other studies on head morphology in newts (Rafinski \& Pecio, 1989). We therefore have no evidence to support the idea that the two newts have developed intersexual differences in feeding strategies along a niche divergence process, as suggested by one version of the ecological model (see e.g. Slatkin, 1984; Shine, 1989; Andersson, 1994). Shine (1989) discussed examples of this model in terms of (1) rate of feeding and (2) type of food consumed. The first category generally assumes that a substantial intersexual difference in body size leads to differences in feeding rates between sexes. The divergence (both in terms of size and type of food consumed) may also be the result of differing reproductive roles of the sexes. Where females are responsible for the larger reproductive investment, they often show a higher feeding rate than males. The second category comprises species where the sexes diverge in trophic morphology as a result of intersexual differences in dietary preferences. Differences in body size between the sexes (e.g. in mean male to female STL ratio) were present in both species examined here, but may be too small to predict sexual differences in feeding habits due to feeding rates alone. Furthermore, it is known that both male and female newts experience high energetic costs during the reproductive season (see e.g. Halliday \& Sweatman, 
1976; Halliday, 1977; Halliday \& Arano, 1991; Griffiths, 1996) and spend considerable time feeding when not involved in courtship. This indicates that feeding rates might be very similar within species, even during the breeding period, suggesting that sexual dimorphism resulting from ecological differences may be negligible, at least in terms of diet. However, one character not included in the present study is the aquatic phase mouth-rim (an upper labial extension), which may have evolved in both sexes to increase feeding success during the breeding period. Studies of niche divergence in $T$. cristatus and $T$. vulgaris have previously concentrated on interspecific differences rather than intersexual (e.g. Dolmen \& Koksvik, 1983; Dolmen, 1988). An exception is Joly \& Giacoma (1992), who included intersexual parameters in their study of a three-species community of newts, and found that prey choice differences were more marked between species than between sexes of the same species.

There were high degrees of sexual dimorphism for body-related characters in both species. The dimorphisms were mostly related to shape, but were to some degree also size-dependent - particularly in T. vulgaris. Size was positively correlated to shape dimorphism (i.e. the calculated regression slopes for sexes diverge, Fig. 2), which is indicative of allometric growth (e.g. Fairbairn, 1997). The separation of specimens in statistical analyses was highly related to sex in both $T$. cristatus and $T$. vulgaris. There were some differences between the two species, for example in which sex had the longer tail, but in general the patterns were very similar. Sexual dimorphism was attributed to females showing large values for dimensions related to fecundity, such as standard length and distance of extremities, contrasted with large values for cloaca and limb-related measurements in males. In all analyses the female 'distance of extremities' measure was highly responsible for the observed patterns, contrasting in $T$. cristatus against the male cloaca and lower hind extremity, and in T. vulgaris against the same measures but in the reversed order of influence. We interpret these results as primarily concordant with the fecundity model. Previous studies on amphibians have shown that females are generally larger than males in body size (e.g. Shine, 1979; Duellman \& Trueb, 1986) possibly because fecundity increases with increasing female body size (but see also Shine, 1988). Males, on the other hand, can often increase their lifetime reproductive success through other life history adaptations in species with little or no male-male aggression, for example by maturing at an early age. Kalezic, Crnobrnja et al. (1992), whose results agree with ours, suggested that the trunk length (corresponding to the distance of extremities) is directly correlated to the length of the pleuroperitoneal cavity. Since this is the space available for maturing eggs, these authors inferred that a larger trunk might be advantageous for female reproductive success. Indeed, Rehak (1983) demonstrated that both $T$. cristatus and T. vulgaris showed a positive allometric increase in the distance of extremities in relation to body size, which was most marked in females. Whether this increase also reflects an associated increase in clutch size, or other reproductive parameters, is as yet undocumented. Most studies have concentrated on relationships between snout-vent length and clutch size (e.g. Verrell \& Francillon, 1986; Hedlund, 1990). Number of eggs, however, may not be the most appropriate measure of the intensity of fecundity selection. Forsman \& Shine (1995) suggested that clutch mass would be a better estimate, since it includes both the number and the size of the eggs in a clutch. This is supported by preliminary evidence on female fecundity in Italian smooth newts Triturus vulgaris meridionalis (Nobili \& Accordi, 1997). Shine (1988) also pointed out that life-history theory assumes that traits should evolve to maximize individual lifetime reproductive success. The 'distance of extremities' measure is perhaps more indicative of female fecundity in Triturus newts, especially if it could be shown to correlate strongly with clutch characteristics such as clutch size, mass or volume. The importance of this trait is also indirectly suggested by male preference for larger females in staged mate-choice experiments in T. vulgaris (Verrell, 1986). Aside from the distance of extremities, other measures are imaginable as useful describers of female fecundity for future studies (e.g. volume, mid-body circumference, width and height), even though they were omitted from this study for practical reasons.

Sexual selection is characterized by individual variation in reproductive success caused by competition over mates (Andersson, 1994). The most well known cases involve the females' active choice of males with enlarged and conspicuous secondary sexual ornaments, but epigamic selection can also be more subtle. We demonstrated that males of both species could be distinguished from females in having larger cloaca and limb-related measures, and also a longer tail in $T$. vulgaris. The cloacal swelling in male newts is most notable laterally and ventrally compared to females, and may be an important factor in male mating success. Most of the cloacal volume is occupied by glands secreting substances forming the spermatophore, though tubules emanating from the pheromone-producing dorsal gland are present - especially in the caudal region of the cloaca (Sever et al., 1990). The dorsal gland itself, which is known to be greatly enlarged during the breeding season in T. vulgaris (Verrell et al., 1986), lies anterior to the pelvic girdle. It is quite likely that both the rate of spermatophore production and the synthesis of courtship pheromones - factors contributing to male mating success - are under the influence of sexual selection, as proposed by Sever et al. (1990), thus affecting the size and volume of structures in the cloacal region. In European newts, studies of sexual selection have focused primarily on secondary sexual traits and lekking behaviour (reviewed by e.g. Halliday, 1977; Halliday \& Arano, 1991; Andersson, 1994; Griffiths, 1996). For example, several authors have demonstrated that female Triturus newts actively choose large males exhibiting conspicuous dorsal crests (Malacarne \& 
Cortassa, 1983; Hedlund, 1990; Green, 1991). However, some difficulties still remains in distinguishing between the contributions of visual versus olfactory cues in newt mate choice (Griffiths, 1996). A large crest may be an indicator of good body condition resulting from foraging efficiency (Baker, 1990, 1992; Green, 1991) and the supposedly high genetic quality of the displaying male. The crest itself also increases the body surface area of the male, which in turn presumably affects the male's ability to transfer pheromones to the female during the display, and enhances the efficiency of cutaneous respiration and endurance - all of which are primary determinants of courtship success (e.g. Halliday \& Sweatman, 1976; Halliday, 1977; Malacarne \& Cortassa, 1983; Hedlund, 1990). Alternatively, the enhanced body surface area of a male with a fully developed dorsal crest may simply be contributing to the male's overall size. Some evidence suggests that female newts may interpret large male size as an indicator of age, survival value or experience. Hedlund (1990), for example, found that large $T$. cristatus males with large crests were more likely to deposit spermatophores that were picked up by the female. She also observed that early in the breeding season, when males' crests were not fully developed, snout-vent length influenced female choice. However, during the most intense lekking period, crest height was the main determinant of mating success. There was a strong correlation in her study between male length and crest height, with the latter trait being the strongest determinant of male mating success. Furthermore, it has also been demonstrated that the number of testes lobes in $T$. cristatus and $T$. vulgaris, is highly correlated with age (Dolmen, 1982). Halliday (1977), argued that females are expected to show a preference for older and correspondingly larger males, if longevity is a good indicator of fitness (see also Kokko, 1997). Other factors that may influence reproductive success for individual male newts are those that contribute to better performance of courtship display (Halliday, 1977). Males of most species of Triturus newts are highly mobile and perform an extensive courtship display in front of the female (e.g. Halliday \& Arano, 1991; Griffiths, 1996). Traits enhancing the active performance of complex movement (e.g. longer legs) can presumably be valuable for individual reproductive success and may be indirectly subjected to sexual selection. It is therefore conceivable that selection for 'lekking performance' can be important for the patterns of sexual dimorphism observed in this study. For example, long limbs, and long tails in T. vulgaris, may improve the performance of males in courtship display. The elongation of limbs in males seems to be particularly marked in T. cristatus. Rehak (1983) demonstrated that there was a relative shortening of extremities with respect to the body in three species of newts, except for male $T$. cristatus, which showed positive allometric growth of posterior extremities. The change of body proportions with increasing size was most marked in females. Rehak concluded that longer limbs might be of great importance in the courtship behaviour of male T. cristatus, suggesting that this trait is under the influence of epigamic selection. It is well known that males of this newt species include an extreme posture in their courtship repertoire - the so-called 'cat buckle' position (see e.g. Halliday, 1977; Griffiths, 1996), where the ability to manoeuvre may be dependent on the posterior limbs.

Although our results on sexual dimorphism presented here mostly favour the fecundity model, the actual underlying selection processes are likely to be more complex. We find it highly probable that sexual dimorphism evolves by routes where factors from more than one evolutionary model work simultaneously on different traits. However, indirect studies of patterns of sexual dimorphism can suggest valuable keys to future studies, which can put these hypotheses to more direct tests.

\section{Acknowledgements}

We express our appreciation to Torkel Hagström at the Göteborg Museum of Natural History (Sweden); Lennart Cederholm at the Zoological Museum of Lund (Sweden); Jens Rasmussen at the Zoological Museum of Copenhagen (Denmark); Torsten Stjernström and Juhani Terhivuo at the Finnish Museum of Natural History (Finland); Erik Åhlander and Sven Kullander at the Swedish Museum of Natural History (Sweden), for loans of specimens. Sincere thanks also to Sven-Åke Berglind, Dag Dolmen and Johan Elmberg for letting us examine specimens from their private collections. We are especially grateful to Mats Olsson, Christopher Raxworthy and an anonymous reviewer, who contributed towards sharpening the focus of the manuscript considerably, and to Claes Andrén and Göran Nilson for comments on earlier drafts. The research was funded by grants to the first author (JCM) from Adolf Lindgrens stiftelse, Helge Ax:son Johnsons stiftelse and Wilhelm \& Martina Lundgrens vetenskapsfond.

\section{REFERENCES}

Andersson, M. (1994). Sexual selection. Princeton: Princeton University Press.

Baker, J. M. R. (1990). Body size and spermatophore production in the smooth newt (Triturus vulgaris). Amphib.-Reptilia 11: $173-184$.

Baker, J. M. R. (1992). Body condition and tail height in great crested newts (Triturus cristatus). Anim. Behav. 43: 157-159.

Darwin, C. (1871). The descent of man, and selection in relation to sex. London: Murray.

Dolmen, D. (1982). Skeletal growth marks and testis lobulation as criteria for age in Triturus spp. (Amphibia) in central Norway. Acta Zool. (Stockh.) 63: 73-80.

Dolmen, D. (1983). Growth and size of Triturus vulgaris and $T$. cristatus (Amphibia) in different parts of Norway. Holarct. Ecol. 6: 356-371. 
Dolmen, D. (1988). Coexistence and niche segregation in the newts Triturus vulgaris (L.) and T. cristatus (Laurenti). Amphib.-Reptilia 9: 365-374.

Dolmen, D. \& Koksvik, J. I. (1983). Food and feeding habits of Triturus vulgaris (L.) and T. cristatus (Laurenti) (Amphibia) in two bog tarns in central Norway. Amphib.-Reptilia 4: 17-24.

Duellman, W. E. \& Trueb, L. (1986). Biology of amphibians. New York: McGraw-Hill.

Endler, J. A. (1983). Natural and sexual selection on color patterns in poeciliid fishes. Environ. Biol. Fishes 9: 173-190.

Fahmy, T. (1997). xlSTAT - data analysis toolbox for Microsoft Excel. Internet (http://www.xlstat.com): Thierry Fahmy.

Fairbairn, D. J. (1997). Allometry for sexual size dimorphism: pattern and process in the coevolution of body size in males and females. Annu. Rev. Ecol. Syst. 28: 659-687.

Forsman, A. \& Shine, R. (1995). Sexual size dimorphism in relation to frequency of reproduction in turtles (Testudines: Emydidae). Copeia 1995: 727-729.

Green, A. J. (1991). Large male crests, an honest indicator of condition, are preferred by female smooth newts, Triturus vulgaris (Salamandridae) at the spermatophore transfer stage. Anim. Behav. 41: 367-369.

Griffiths, R. A. (1996). Newts and salamanders of Europe. London: $\mathrm{T} \& \mathrm{AD}$ Poyser.

Halliday, T. R. (1977). The courtship of European newts: an evolutionary perspective. In The reproductive biology of Amphibians: 185-232. Taylor, D. H. \& Guttman, S. I. (Eds). New York: Plenum Press.

Halliday, T. \& Arano, B. (1991). Resolving the phylogeny of the European newts. Trends Ecol. Evol. 6: 113-117.

Halliday, T. R. \& Sweatman, H. P. A. (1976). To breathe or not to breathe; the newt's problem. Anim. Behav. 24: 551-561.

Halliday, T. R. \& Verrell, P. A. (1986). Sexual selection and body size in amphibians. Herpetol. J. 1: 86-92.

Hedlund, L. (1990). Reproductive ecology of crested newts, Triturus cristatus (Laur.). Dissertation, Swedish University of Agricultural Sciences, Uppsala.

Hedrick, A. V. \& Temeles, E. J. (1989). The evolution of sexual dimorphism in animals: hypotheses and tests. Trends Ecol. Evol. 4: 136-138.

Jackson, J. E. (1991). A user's guide to principal components. New York: John Wiley.

Joly, P. \& Giacoma, C. (1992). Limitation of similarity and feeding habits in three syntopic species of newts (Triturus, Amphibia). Ecography 15: 410-411.

Kalezic, M. L., Crnobrnja, J., Dorovic, A.\& Dzukic, G. (1992). Sexual size difference in Triturus newts: geographical variation in Yugoslav populations. Alytes 10: 63-80.

Kalezic, M. L., Dzucic, G., Stamenkovic, S. \& Crnobrnja, J. (1990). Morphometrics of the crested newt (Triturus cristatus complex) from Yugoslavia: relevance for taxonomy. Arh. Biol. Nauka (Beograd) 42: 17-37.

Kokko, H. (1997). Evolution of honest sexual displays. Dissertation, University of Helsinki, Finland.

Mace, G. (1992). Differences between the sexes. In The Cambridge encyclopedia of human evolution: 52-55. Jones, S.,
Martin, R. \& Pilbeam, D. (Eds). Cambridge: Cambridge University Press.

Malacarne, G. \& Cortassa, R. (1983). Sexual selection in the crested newt. Anim. Behav. 31: 1256-1257.

Manly, B. F. J. (1994). Multivariate statistical methods - a primer. 2nd edn. London: Chapman \& Hall.

Maynard Smith, J. (1989). Evolutionary genetics. Oxford: Oxford University Press.

Nobili, G. \& Accordi, F. (1997). Body size, age and fecundity variation in different populations of the smooth newt Triturus vulgaris meridionalis in central Italy. Ital. J. Zool. 64: 313-318.

Rafinski, J. \& Pecio, A. (1989). Craniometric studies on the species of the genus Triturus, Rafinesque, 1815 (Amphibia, Salamandridae). Folia Biol. (Krakow) 37: 131-150.

Raxworthy, C. J. (1989). Courtship, fighting and sexual dimorphism of the banded newt, Triturus vittatus ophryticus. Ethology 81: 148-170.

Raxworthy, C. J. (1990). A review of the smooth newt (Triturus vulgaris) subspecies, including an identification key. Herpetol. J. 1: 481-492.

Rehak, I. (1983). Changes in body measures during the growth of the newts Triturus vulgaris, T. alpestris and T. cristatus (Amphibia: Urodela). Vest. cs. Spolec. zool. 47: 51-67.

Reynolds, J. D. \& Harvey, P. H. (1994). Sexual selection and the evolution of sex differences. In The differences between the sexes: 53-70. Short, R. V. \& Balaban, E. (Eds). Cambridge: Cambridge University Press.

Sever, D. M., Verrell, P. A., Halliday, T. R., Griffiths, M. \& Waights, V. (1990). The cloaca and cloacal glands of the male smooth newt, Triturus vulgaris vulgaris (Linnaeus), with especial emphasis on the dorsal gland. Herpetologica 46: 160-168.

Shine, R. (1979). Sexual selection and sexual dimorphism in the Amphibia. Copeia 1979: 297-306.

Shine, R. (1988). The evolution of large body size in females: a critique of Darwin's 'fecundity advantage' model. Am. Nat. 131: $124-131$.

Shine, R. (1989). Ecological causes for the evolution of sexual dimorphism: a review of the evidence. Q. Rev. Biol. 64: 419461.

Shine, R. (1990). Proximate determinants of sexual differences in adult body size. Am. Nat. 135: 278-283.

Slatkin, M. (1984). Ecological causes of sexual dimorphism. Evolution 38: 135-139.

Verrell, P. A. (1985). Getting into a pickle with preserved specimens: formalin and distortion in the smooth newt, Triturus vulgaris. Herpetol. J. 1: 39-40.

Verrell, P. A. (1986). Male discrimination of larger, more fecund females in the smooth newt, Triturus vulgaris. J. Herpetol. 20: 416-422.

Verrell, P. A. \& Francillon, H. (1986). Body size, age and reproduction in the smooth newt, Triturus vulgaris. J. Zool. (Lond.) 210: 89-100.

Verrell, P. A., Halliday, T. R. \& Griffiths, M. L. (1986). The annual reproductive cycle of the smooth newt (Triturus vulgaris) in England. J. Zool. (Lond.) 210: 101-119. 
Appendix. Material examined

Triturus cristatus (114 specimens): University of Copenhagen Zoological Museum, Denmark: R80133, R80152, R80159, R80320，R80321，R80361，R80362，R8055，R8062，R8063; Finnish Museum of Natural History, Finland: 1, 3, 4, 5, 6, 11, 654, 659; Göteborg Museum of Natural History, Sweden: BARESU 48, 127, 128, 213, 214, 316, 351, 376, 419, 420, 421, 732, 949; University of Lund Zoological Museum, Sweden: L50 3193A, L50 3193B, L50 3193C, L937 3068A, L937 3068B, L943 3065, L949 3184A, L949 3184B, L949 3184C, L951 3393A, L951 3393B, L961 3125A, L961 3125B; Swedish Museum of Natural History, Sweden: 1413, 10156, 10416, 38985; Sven-Ake Berglind private collection, Sweden: 910731; University of Trondheim Dag Dolmen collection, Norway: 317A 5, 317A 24, 317A 33, 317A 34, 317A 35, 317B 40, 317B 41, 317B 45, 317B 46, 317B 48, 317D 76, 317D 77, 317D 79, 317D 89, 317D 90, 317E 113, 317E 116, 317E 117, 317F 118, 317F 119, 317F 126, 317F 127, 317F 134, 317L 288, 317L 289, 317L 290, 317L 291, 318A I, 318A II, 318A III, 318A VIII, 318A X, 318A XII, 318B XLII, 318C LXIV, 318C LXV, 318C XLIII, 318D CII, 318D CIII, 318D XCVI, 318D XCVII.
Triturus vulgaris (160 specimens): University of Copenhagen Zoological Museum, Denmark: R0345, R0370, R8073, R8074, R8075, R80447, R80448, R80449; Finnish Museum of Natural History, Finland: 21, 33, 37, 72, 534, 627, 628; Göteborg Museum of Natural History, Sweden: BARESU 67, 68, 123, 125, 216, 317, 365, 366, 367, 368, 422, 522, 581a, 581b, 992, UTL 89; Johan Elmberg private collection, Sweden: 801, 802, 803, 805, 806, 808, 810, 812, 813, 814; Swedish Museum of Natural History, Sweden: 10187, 10210, 13050; University of Trondheim Dag Dolmen collection, Norway: 314-315A 175, 314-315A 176, 314-315A 177, 314-315B 179, 314-315B 180, 314-315B 186, 314-315B 187, 314-315B 188, 314-315B 189, 314-315B 191, 314-315B 195, 314-315B 196, 314-315B 225, 314-315B 226, 314-315B 227, 314-315B 229, 314-315B 230, 314-315B 234, 314-315B 235, 314-315C 237, 314-315C 239, $314-315 \mathrm{C} 241,314-315 \mathrm{C} 242,314-315 \mathrm{C} 252,314-315 \mathrm{C} 257$, $314-315 \mathrm{C} 258,314-315 \mathrm{C} 261,314-315 \mathrm{C} 263,314-315 \mathrm{C} 269$, 314-315G 504, 314-315G 505, 314-315G 506, 314-315G 508, $314-315 \mathrm{G} \quad 515,314-315 \mathrm{~K}$ 1061, 314-315K 1062, 314-315K $1066,314-315 \mathrm{~K} \quad 1071,314-315 \mathrm{~K} \quad 1076,314-315 \mathrm{P} \quad 1028$, 314-315P 1047, 314-315P 1049, 316A II, 316A III, 316A V, 316A VI. 